\title{
Mevlana Türbesi Civarında Oluşan Kentsel Gelişim ve Değişimlerin Hava Fotogrametrisi Verilerinden Yararlanarak Görüntülenmesi
}

\author{
Urban Growing and Change Visualization in Mevlana Region Using Spatial Data from \\ Aerial Images
}

\author{
Cihan ALTUNTAŞ*
}

Konya Teknik Üniversitesi, Mühendislik ve Doğa Bilimleri Fakültesi, Harita Mühendisliği Bölümü, 42075, Konya

• Geliş tarihi / Received: 25.09.2018 • Düzeltilerek geliş tarihi / Received in revised form: $25.01 .2019 \quad$ • Kabul tarihi / Accepted: 18.02 .2019

$\ddot{O} \mathbf{z}$

Fotogrametrik görüntülerden otomatik olarak tanımlanan yerel özellik noktaları ile görüntüler arasında eşlenik noktalar oluşturulabilmekte ve fotogrametrik bağıntılar yardımı ile istenilen sıklıkta nokta ölçüsü gerçekleștirilebilmektedir. Fotoğraflardan elde edilen ölçü noktalarının oluşturduğu nokta bulutu araziye ait zengin konum bilgisi içermektedir. Diğer yandan ardışık nokta bulutu ölçülerinin karşılaştırılması ile görüntü alanına ait değişiklikler tespit edilebilir. Bu çalışmada Konya ili Mevlana Türbesi civarında oluşan kentsel değişimler incelenmiştir. 1951, 1975 ve 2010 yıllarına ait fotogrametrik görüntülerden yoğun nokta bulutları oluşturulmuş ve nokta bulutları arasındaki düşey farklar ile kentsel alan değişimleri görüntülenmiştir. Ayrıca ölçü periyotlarına ait ortofoto görüntüler oluşturularak değişimlerin görsel olarak değerlendirilebilmesi sağlanmıştır.

Anahtar kelimeler: Fotogrametri, Hava fotoğrafi, Kentsel değişim, Ortofoto, Yoğun nokta bulutu

\begin{abstract}
Keypoints which is detected automatically from images enable conjugate points creation between photogrammetric images, and dense point cloud can be generated by proceeding the photogrammetric process. The dense point cloud data includes many spatial information related to imaging area. On the other hand topographic changes can be detected by comparing two periods of point clouds. In this study urban changes in Mevlana region of Konya city was visualized by comparing three periods of point clouds belong the year 1951, 1975 and 2010. The urban changes were estimated with the vertical distances between compared point clouds. In addition, orthophoto images were created for analysing the related changes.
\end{abstract}

Keywords: Photogrammetry, Aerial image, Urban change, Dense point cloud, Orthophoto

\footnotetext{
* Cihan ALTUNTAŞ; caltuntas@selcuk.edu.tr; Tel: (0332) 22318 94; orcid.org/0000-0002-5754-2068
} 


\section{Giriş}

Üç boyutlu (3B) nokta bulutu oluşturma pek çok alanda ihtiyaç duyulan yaygın bir ölçme yöntemi haline gelmiştir. Özellikle 3B modelleme çalışmalarında ve ölçme alanına ait daha fazla bilgiye ihtiyaç duyulduğunda nokta bulutu oluşturacak şekilde ölçü gerçekleştirilmektedir. Arazi topoğrafyasına ait nokta bulutu ölçüleri LiDAR (Light Detection and Ranging), SAR (Synthetic Aperture Radar) ve fotogrametrik görüntülerden elde edilebilmektedir. Havadan ve yerden yapılan mobil LiDAR yönteminde ölçme aletinin kabiliyetine bağlı olarak arazi topoğrafyası belirli bir nokta sıklığı ile ölçülür (Ghuffar vd., 2013). Ölçme doğruluğu iyi ancak maliyetinin yüksek olması nedeniyle kolay ulaşılabilir bir ölçme yöntemi değildir. SAR yönteminde arazi yüzeyi belirli aralıkta gridlere bölünerek ölçülür. Grid aralıkları çok kısa olmadığından geniş arazi topoğrafyalarının ölçümü için uygundur (Bildirici vd., 2009). SAR uydu bazlı bir ölçme tekniğidir ve ölçü doğruluğu LiDAR yöntemine göre düşüktür. Oysa fotogrametri yöntemi düşük maliyetli ve yüksek doğrulukta ölçü yapabilme imkânı sağlar. Fotogrametrik yöntemde stereo görüntüler uçak, helikopter, insansız hava aracı (iHA) ve yersel yöntemlerle elde edilir. Geliştirilen yeni değerlendirme teknikleri ile görüntülerden ölçü verisi elde etmede otomatik yöntemler uygulanmaktadır ve yoğun nokta bulutu verisi çok kısa sürede oluşturulabilmektedir. Fotogrametrik görüntülerden yoğun nokta bulutu oluşturma düşük maliyetli ve kolay uygulanabilen bir yöntemdir. Fotogrametrik nokta bulutunun doğruluğu ise oldukça yüksektir ve pek çok araştırmada kullanılmıştır (Rosnell ve Honkavaara, 2012; Haala, 2011). Nokta yoğunluğu, doğruluk ve maliyet bakımından karşılaştırıldığında fotogrametrik nokta bulutu LiDAR yöntemine göre daha üstündür. Fotogrametrik yöntemde ölçme doğruluğu bir piksel büyüklügünden daha iyi seviyededir. Nokta yoğunluğu ise LiDAR yöntemine göre daha fazladır. Diğer yandan fotoğrafın içerdiği zengin semantik bilgi fotogrametrik yöntemi öne çıkaran özelliklerdendir (Leberl vd., 2010). Ancak eşlenik nokta oluşturulabilecek detayların az olduğu su yüzeyi ve ekili alanlarda yeterli sayıda nokta üretmek sorun olabilmektedir.

Fotogrametrik nokta bulutu oluşturma, haritalama, kent modelleme, ziraat, ormanc1lık ve doğal afetlerin oluşturduğu zararların görüntülenmesi gibi pek çok alanda kullanılmıştır. Yang vd. (2013) otomatik görüntü eşleme yöntemi ile sanal gerçeklik uygulamasını farklı boyutlarda iç ve dış mekân objeleri için yapmış ve işlem adımlarını detaylı olarak tanımlamıştır. Jensen ve Mathews (2016) İHA ile alınan görüntüleri kullanarak fotogrametrik nokta bulutu ile sayısal yükseklik modeli (SYM) üretmişler ve ağaç yüksekliklerini belirlemişlerdir. Aynı işlem LiDAR verileri kullanılarak da yapılmış ve iki yöntem ile üretilen SYM arasında ortalama $19 \mathrm{~cm}$ fark olduğu belirtilmiştir. Orman alanındaki büyük çaplı değişiklikler hava fotoğraflarından üretilen yoğun nokta bulutu ile tespit edilebilirken tek ağaç gibi küçük değişiklikler tespit edilememiştir. Ancak yine de orman alanlarındaki değişikliklerin izlenmesinde fotogrametrik yoğun nokta bulutu yönteminin diğer yöntemlere göre tercih edilebilir olduğu ifade edilmiştir (Sisto ve Packalen, 2017). Diğer bir çalışmada uçaktan ve İHA ile alınan görüntülerden üretilen SYM ile doğal afet zararların tespiti yapılmıştır (Cusicanqui, 2016). Benzer bir çalışmada İHA ile alınan görüntülerden üretilen nokta bulutu ile hacim karşılaştırması yapılarak toprak kaymas1 nedeniyle oluşan değişiklikler $12 \mathrm{~cm}$ karesel ortalama hata $(\mathrm{KOH})$ ile tespit edilmiştir (Al-Rawabdeh vd., 2017).

Başka bir çalışmada ise iki farklı tarihli hava fotoğrafı ile yapılaşmış ve yapılaşmamış alanlardaki değişiklikler tespit edilmiştir. Değişikliklerin belirlenebilmesi için zeminde tespit edilen detaylar ikili (binary) kodlara dönüştürülerek değişime uğrayanlar ve uğramayanlar olarak sınıflandırılmıştır. Özellikle yeni bina, kat eklenmesi ve yıkılan binalar detaylı olarak tespit edilebilmiştir (Pang vd., 2018). Binaların oluşturduğu değişim LiDAR verisinden düzlem yüzeylerin segmentasyonu ile de tespit edilmiştir (Awrangjeb vd., 2015). Nebiker vd. (2014) kentsel alanda yeni yapılan binaları fotogrametrik yoğun nokta bulutu ve LiDAR verilerinden tespit etmiştir. Benzer bir çalışmada eski tarihli hava fotoğraflarının yoğun nokta bulutu ile yeni tarihli LiDAR ölçüsü karşılaştırılarak yeni binalar ve oluşan değişiklikler tespit edilmiştir ( $\mathrm{Du}$ vd., 2016). Uydu fotoğraflarından üretilen yoğun nokta bulutu ile LiDAR ölçüsü karşılaştırılarak yapılan çalışmada ise oluşan değişiklikler $\% 90$ doğruluk ile tespit edilmiştir (Basgall vd., 2014).

Kentsel alanlarda oluşan değişimler yapılaşma, ilave kat, kazı ve dolgu gibi faaliyetler sonucu ortaya çımaktadır. Kentsel alanlardaki değişikliklerin izlenmesi kentin tarihi gelişim sürecinin görüntülenmesi yanında kentsel denetimlerin etkili bir şekilde yapılmasını sağlayacaktır. Kentin tarihi süreçte geçirdiği 
değişim bundan sonraki planlama çalışmalarına da 1 şık tutacaktır. Diğer yandan kentsel denetim kapsamında kaçak bina, izinsiz kazı ve hafriyat atığı depolama alanları tespit edilebilecek ve gerekli önlemler alınacaktır. Ayrıca deprem gibi doğal afetler nedeniyle oluşan hasarlar ve topoğrafya değişimlerinin hızlı bir şekilde tespit edilmesi müdahale ve yardım çalışmalarını kolaylaştıracaktır. Bu çalışmada Konya Mevlana Müzesi ve çevresinde oluşan kentsel değişimler 1951, 1975 ve 2010 y1l stereo hava fotoğraflarından üretilen nokta bulutları karşılaştırılarak görüntülenmiştir. Makalenin ikinci bölümünde çalışma alanı tanımlanmış, üçüncü bölümde kullanılan yöntemler açıklanmış, dördüncü bölümde elde edilen sonuçlar verilmiştir. Beşinci ve altıncı bölümlerde ise sırasıyla tartışma ve sonuç bölümleri verilmiştir.

\section{2. Çalışma Alanı}

Çalışma bölgesi, Mevlana Müzesini içine alan 37०51'59.4294929"K, 32²9'51.647973"D ve 37 $52^{\prime} 25.4936427^{\prime \prime K}, \quad 32^{\circ} 30^{\prime} 19.2943553 " \mathrm{D}$ coğrafi koordinatlarının sinırlandırdığı alandır. Boyutları doğu-batı yönünde $680 \mathrm{~m}$ ve kuzeygüney yönünde $800 \mathrm{~m}$ dir. Çalışma alanının büyük kısmı konut ve işyeri binalarından oluşmakta, ayrica asfalt kara yolu ve mezarlık alanı bulunmaktadır (Şekil 1).

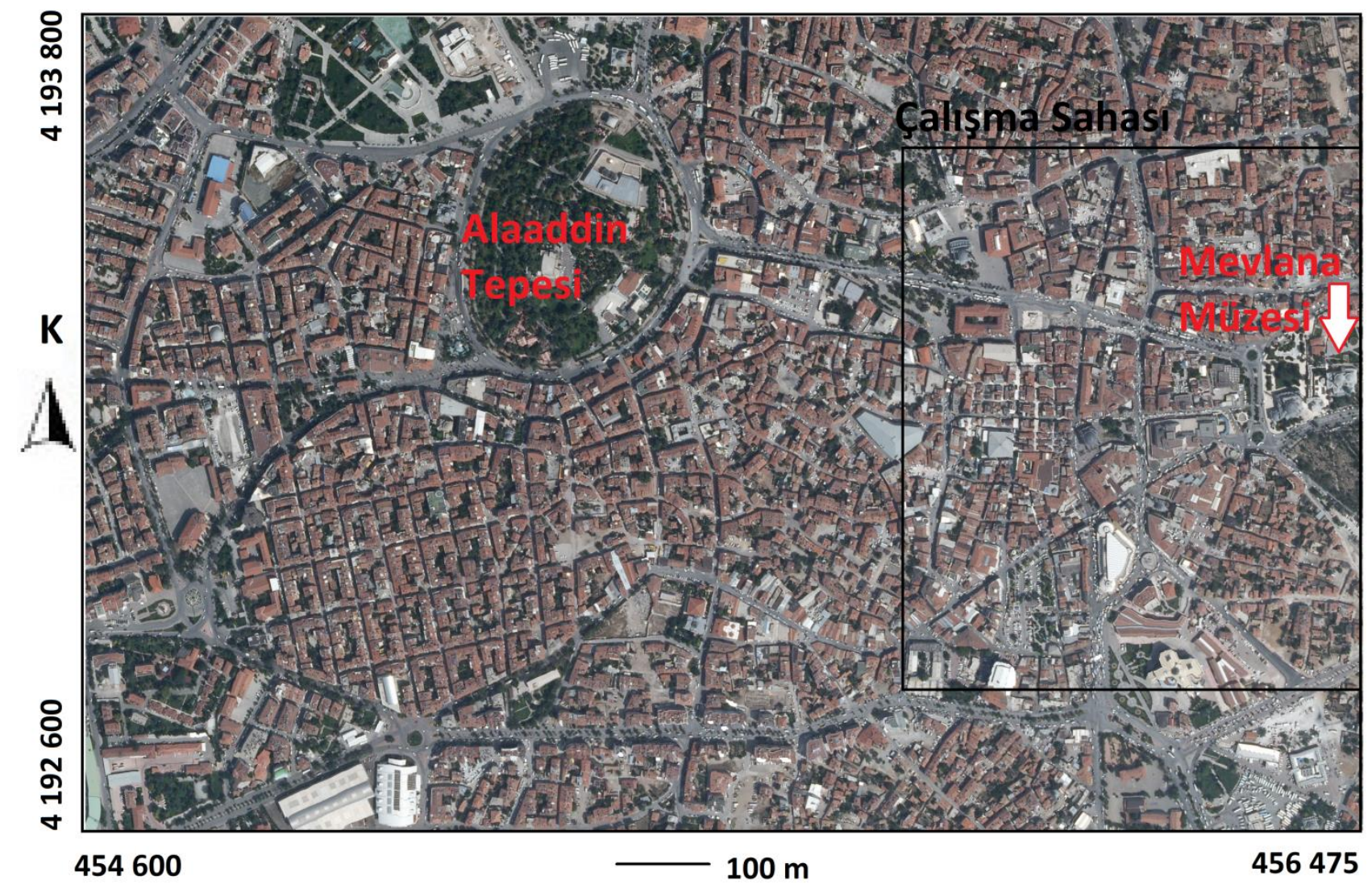

Şekil 1. Çalışma sahası (Harita kaynağı: Google Earth)

\section{Materyal ve Metot}

Stereo görüntülerden oluşturulan nokta bulutu ile sayısal yüzey modeli oluşturulabilir ve farklı tarihli sayısal yüzey modellerinin karşılaştırılması ile bu tarihler arasında oluşan değişiklikler tespit edilebilir. Jeodezik koordinatlandırma, fotoğraflardan oluşturulan nokta bulutunun hem ölçeklendirilmesini hem de ortak bir koordinat sisteminde ifade edilmesini sağlar. Nokta bulutları jeodezik koordinat sistemine dönüştürüldükten sonra İteratif En Yakın Nokta (IEYN) yöntemi ile hassas yöneltmesi yapılarak birleştirilir ve görüntüleme tarihleri arasında oluşan değişiklikler tespit edilir. Çalışma kapsamında takip edilen temel işlem adımları şu şekildedir:

1. Değişim incelenecek zaman aralığının başlangıç ve bitiş tarihlerine ait stereo görüntülerin elde edilmesi (1951, 1975, 2010 tarihleri)

2. Oluşturulacak nokta bulutu koordinatlarının jeodezik koordinat sistemine dönüşümü için detay noktalarından Yer Kontrol Noktas 1 
(YKN) oluşturma ve koordinatlarının ölçülmesi

3. Fotogrametrik görüntülerden yoğun nokta bulutu oluşturma

4. Yoğun nokta bulutunun YKN ile jeodezik koordinat sistemine dönüştürülmesi

5. Değişim incelenecek periyodun yeni tarihli nokta bulutunun eski tarihli nokta bulutu koordinat sistemine IEYN yöntemi ile hassas dönüşümü

6. Yeni tarihli nokta bulutundan eski tarihli nokta bulutuna olan düşey mesafeler hesaplanarak değişimlerin tespiti ve görüntülenmesi.

\subsection{Hava Fotoğraflarının Temini}

Çalışma alanını kapsayan 1951, 1975 ve 2010 yıllarına ait stereo hava fotoğrafları Harita Genel Müdürlüğü (HGM)' den temin edilmiștir. 1951 ve 1975 tarihli hava fotoğrafları analog kameralar ile çekilmiş ve daha sonra HGM de film tarayıcı ile sayısallaştırılarak dijital ortama aktarılmıştır. Fotoğraflara ait herhangi bir kamera kalibrasyon bilgisi ve diş yöneltme parametreleri edinilememiştir. 2010 yılı görüntüsü ise dijital hava kamerası ile çekilmiştir. Hava fotoğraflarına ait bilgiler Tablo 1 de verilmiştir.

Tablo 1. Hava fotoğraflarına ait bilgiler

\begin{tabular}{llll}
\hline $\begin{array}{l}\text { Çekim } \\
\text { Tarihi }\end{array}$ & $\begin{array}{l}\text { Hava } \\
\text { Kamerası } \\
\text { Tipi }\end{array}$ & $\begin{array}{l}\text { Odak } \\
\text { Uzaklığı } \\
(\mathbf{m m})\end{array}$ & $\begin{array}{l}\text { Resim/Görüntü } \\
\text { Boyutları }\end{array}$ \\
\hline 1951 & Analog & 204.18 & $18 \times 18 \mathrm{~cm}$ \\
1975 & Analog & 208.17 & $18 \times 18 \mathrm{~cm}$ \\
2010 & $\begin{array}{l}\text { Dijital } \\
\text { (UltraCamX) }\end{array}$ & 100.50 & $\begin{array}{l}9420 \times 14430 \\
\text { piksel } \\
7.20 \text { mikron }\end{array}$ \\
\hline
\end{tabular}

\subsection{YKN Oluşturma}

YKN, hava fotoğraflarından oluşturulan nokta bulutunun jeodezik koordinat sistemine dönüştürülmesi için gereklidir. Fotoğrafların kapladığ1 alanda önceden tesis edilmiş YKN bulunmamakta ve diş yöneltme parametreleri bilinmemektedir. $\mathrm{Bu}$ durumda fotoğrafların yöneltme işlemleri stereoskopik görüntü alanındaki detaylardan YKN oluşturularak yapılmıştır. Oluş̧urulan YKN hem fotoğraftan seçilebilmeli hem de arazide mevcut bir detay noktası olmalıdır. $\mathrm{Bu}$ özellikleri taşıyan bina duvarı, bahçe duvarı, kavşaklar ve benzeri detaylar seçilerek YKN oluşturulmuştur (Şekil 2). Seçilen bir detay üç farklı tarihli görüntülerin tamamında tespit edilemediğinden her görüntü için farklı YKN tesis edilmiştir. Sonuçta oluşturulan YKN den bir kısmı yalnız ilgili görüntüye ait iken bazıları bütün stereoskopik görüntülerde ortaktır. Eski tarihli fotoğraflar için yapılaşmamış boş arazilerde YKN tesisi zordur. Ancak Konya tarihi bir kent olması nedeniyle çok sayıda tarihi esere sahiptir ve bu yapilar kullanılarak yeterli sayıda YKN tesis edilebilmiştir. Toplam 19 YKN tesis edilmiş ve bunların jeodezik koordinatları GNSS alıcıları ile ölçülmüştür.

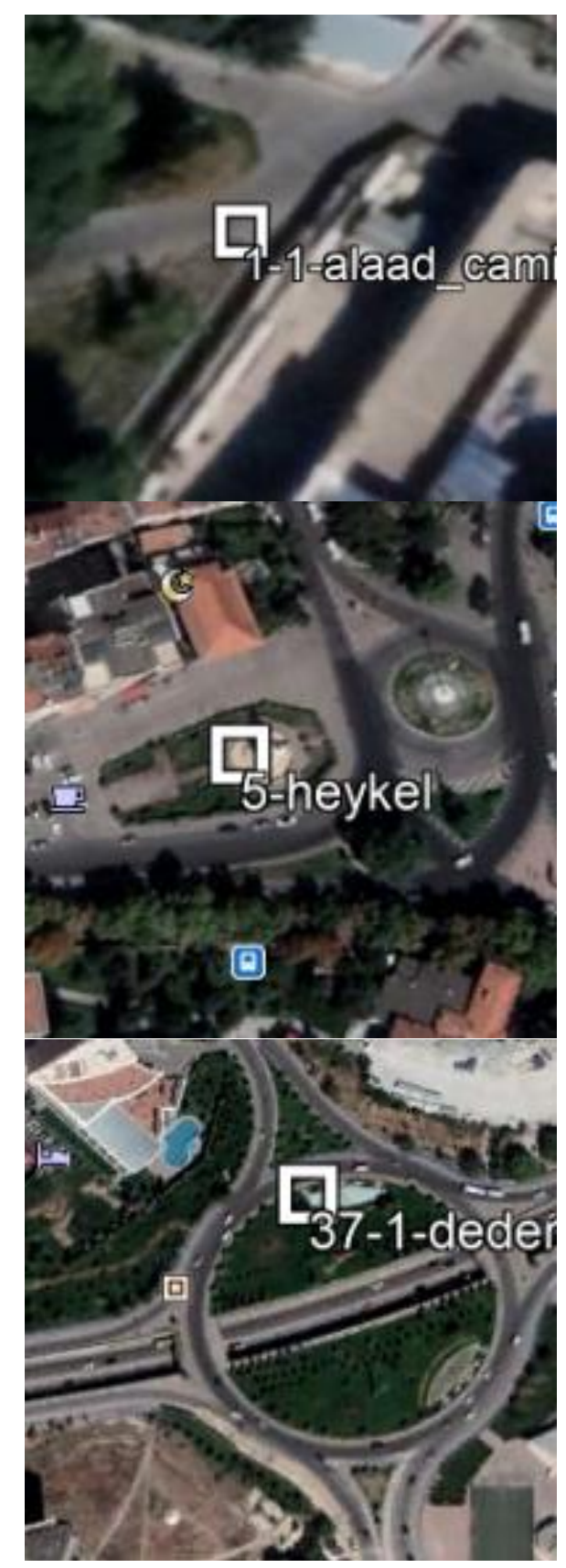

Şekil 2. Yer kontrol noktası olarak seçilen detay noktalarından örnekler 


\subsection{Kentsel Değişimlerin Tespiti}

Ardışık iki nokta bulutu arasındaki farklar bu tarihler arasında oluşan kentsel değişimleri ifade eder. Nokta bulutları arasındaki farkların hesaplanmasinda noktadan noktaya, noktadan yüzeye (mesh üçgen yüzeyi elemanı) olan mesafeler kullanılmakta ve filtreleme, bulanık mantık ve İEYN algoritması kullanılarak gerçekleştirilmektedir. Noktadan yüzeye olan mesafelerin hesaplanmasında nokta dağılımındaki düzensizliklerin ve boşlukların sonuca olumsuz etkisi olmamaktadır. Cisim bazında oluşan kentsel değişimler bu yöntem ile otomatik olarak tespit edilebilmiştir. Kısa zaman aralığında oluşan küçük değişiklikler ve geniş zaman aralığında oluşan büyük değişiklikler noktadan yüzeye olan mesafeler hesaplanarak tespit edilebilmiştir (Xiao vd., 2015; Barnhart ve Crosby, 2013). Grid yönteminde ölçme verisi düzgün aralıklar oluşturacak şekilde yeniden örneklenir ve grid yüzeylerinin karşılaştırılması ile değişiklikler tespit edilir (Scaioni vd., 2013). Makine öğrenmesi yönteminde ise çalışma alanı farklı sinıflara bölünerek 3B ölçme verisi karşılaştırılmaktadır ve $\% 90$ seviyesinde doğruluk elde edilmiştir (Tran vd., 2018).

IEEYN yönteminde, yaklaşık yöneltmesi yapılmış ortak tarama alanına sahip iki nokta seti arasındaki eşlenik en yakın nokta çiftleri bulunur ve bunlarla hassas dönüşüm iteratif olarak uygulanır. İEYN algoritmasinın (Chen ve Medioni, 1992) farklı uygulamaları çok sayıda çalışmada değişikliklerin tespiti için kullanılmıştır. Depremlerin meydana getirdiği zararlar ve değişiklikler deprem öncesi ve sonrası LiDAR nokta bulutlarının IEEN uygulanarak karşılaştırılması ile elde edilmiştir. LiDAR ölçülerinin birleştirilmesi $0.44 \mathrm{~m}$ hata ile gerçekleştirilmiştir (Zhang vd., 2015).

$\mathrm{Bu}$ çalışmada iki nokta bulutu İEYN ile birleştirildikten sonra hedef nokta bulutu noktalarının referans nokta bulutunun mesh yüzeyine olan mesafeleri ile değişiklikler görüntülenmiştir.

\section{Sonuçlar}

\subsection{Nokta Bulutu Oluşturma}

SfM algoritması kullanılarak yöneltme parametreleri hesaplanan görüntü setinden, daha fazla sayıda eşlenik nokta oluşturularak fotogrametrik bağıntılarla yoğun nokta bulutu oluşturulur. SfM algoritması çoklu görüntü setinden belirli özellikteki görüntü noktalarının otomatik tespiti ve eşleştirilmesi ile detay noktalarının ve kamera konumlarının tanımlı bir görüntü koordinat sisteminde ifade edilmesidir. $\mathrm{Bu}$ işlemde kamera parametreleri, resim dönüklükleri ve eşlenik resim noktalarının 3B koordinatları ışın demetleri dengelemesi ile iteratif olarak hesaplanmaktadır. Kolay ve hizlı uygulanabilmesi ve özel maliyet gerektirmemesi nedeniyle fotoğraftan nokta bulutu oluşturma geniş bir uygulama alanına sahiptir.

Stereoskopik görüntülerden nokta bulutu oluşturmak için Agisoft Photoscan yazılımı kullanılmıştır. Fotoğraflara ait kalibrasyon bilgileri olmadığından iç yöneltme parametreleri olmadan nokta bulutu oluşturma işlemi gerçekleştirilmiştir. Görüntülerin eşleştirilmesi ile seyrek nokta bulutu oluşturulduktan sonra yoğun nokta bulutu oluşturulmuştur (Tablo 2). Yoğun nokta bulutu oluşturma süresi nokta sayısı ile orantılıdır ve en az nokta üretilen 1951 y1lı için 17 saniye, en fazla nokta üretilen 2010 y1lı için 27 saniyedir. 1975 yılı yoğun nokta bulutu verisi üç adet fotoğrafin stereoskopik alanından üretilmiştir. $\mathrm{Bu}$ nedenle yoğun nokta bulutu oluşturma süresi diğerlerinden fazladır ve 1 dakika 42 saniye sürmüştür. Photoscan yazılımı yoğun nokta bulutu oluşturmada çeşitli seçenekler sunmaktadır. Bu çalışmada "Medium" (orta yoğunluk) seçeneği ile nokta bulutu oluşturulmuştur. Ayrica "Advanced" penceresi hatalı olabilecek noktaların ayıklanmasında ileri seçenekler sunar. Bunlardan, çalışma içeriği bakımından küçük detayların çok önemli olmadığ 1 "Aggressive" seçeneği kullanılmıștır (Şekil 3).

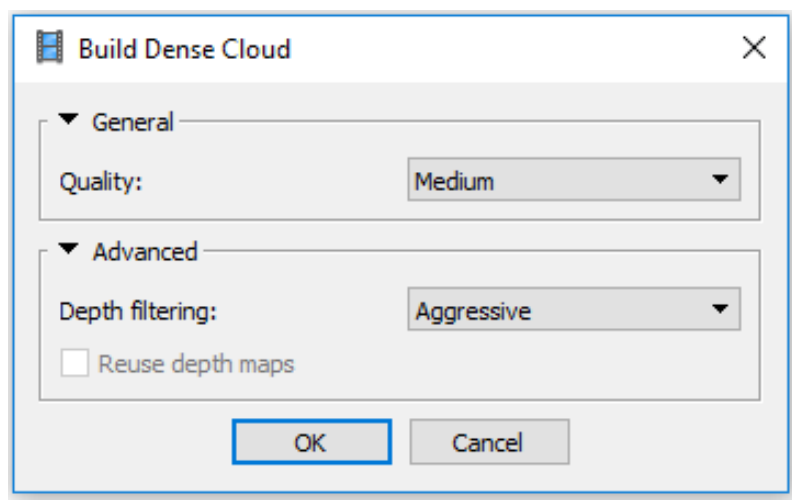

Şekil 3. Yoğun nokta bulutu oluşturma ayarları penceresi

Yüksek binaların oluşturduğu gölgeleme etkisi nedeniyle nokta bulutlarında boşluklar oluşmaktadır. Diğer yandan eşlenik nokta oluşturulamayan alanlarda (cam kaplı binalar gibi) 
da boşluklar oluşmaktadır. Ancak çalışma alanında bu tür yüzeylerden kaynaklanan üretilmeyen enterpolasyon alanlar komşu alanlardan boşluklar oluşmadığı değerlendirilmiştir. Nokta doldurulmuştur.

Tablo 2. Nokta bulutu oluşturma işlemine ait sonuçlar

\begin{tabular}{llll}
\hline & Yll 1951 & Yll 1975 & Yll 2010 \\
\hline Fotoğraf sayısı\# & 2 & 3 & 2 \\
Uçuş kotu & $6.27 \mathrm{~km}$ & $7.26 \mathrm{~km}$ & $8.05 \mathrm{~km}$ \\
Yer çözünürlüğü & $73.4 \mathrm{~cm} /$ piksel & $40.3 \mathrm{~cm} /$ piksel & $50.2 \mathrm{~cm} /$ piksel \\
Stereo alan & $27.6 \mathrm{~km}{ }^{2}$ & $22.7 \mathrm{~km}^{2}$ & $21.7 \mathrm{~km}$ \\
Eşleme noktaları & $16160 f 1756$ & 6527 of6655 & 3870 of3994 \\
Nokta 1şını sayısı & 3232 & 13487 & 7740 \\
Resim koor. hatası & 0.989 piksel & 0.867 piksel & 0.259 piksel \\
Max.resim koor. hatası & 5804 piksel & 8034 piksel & 1910 piksel \\
Yoğun nokta sayısı & 2539040 & 8859870 & 5243623 \\
\hline
\end{tabular}

\subsection{Jeodezik Koordinatlandırma}

Her nokta bulutu yeterli sayıda YKN ile jeodezik koordinat sistemine dönüştürülmüştür. Dönüşüm sonunda YKN da oluşan artık hatalar ile dönüşümün doğruluğu değerlendirilmiştir. Elde edilen koordinat farkları dönüşümün yüksek doğrulukta yapıldığını göstermektedir (Şekil 4, Tablo 3). Detay YKN kullanılan benzer çalışmalarla kiyaslandığında jeodezik koordinatlandırma yüksek doğrulukla yapılmıştır (Nebiker vd., 2014; Hughes vd., 2006). Diğer yandan resimlerin bağlantı noktalarındaki artık hatalar ise 1 pikselden daha düşüktür.

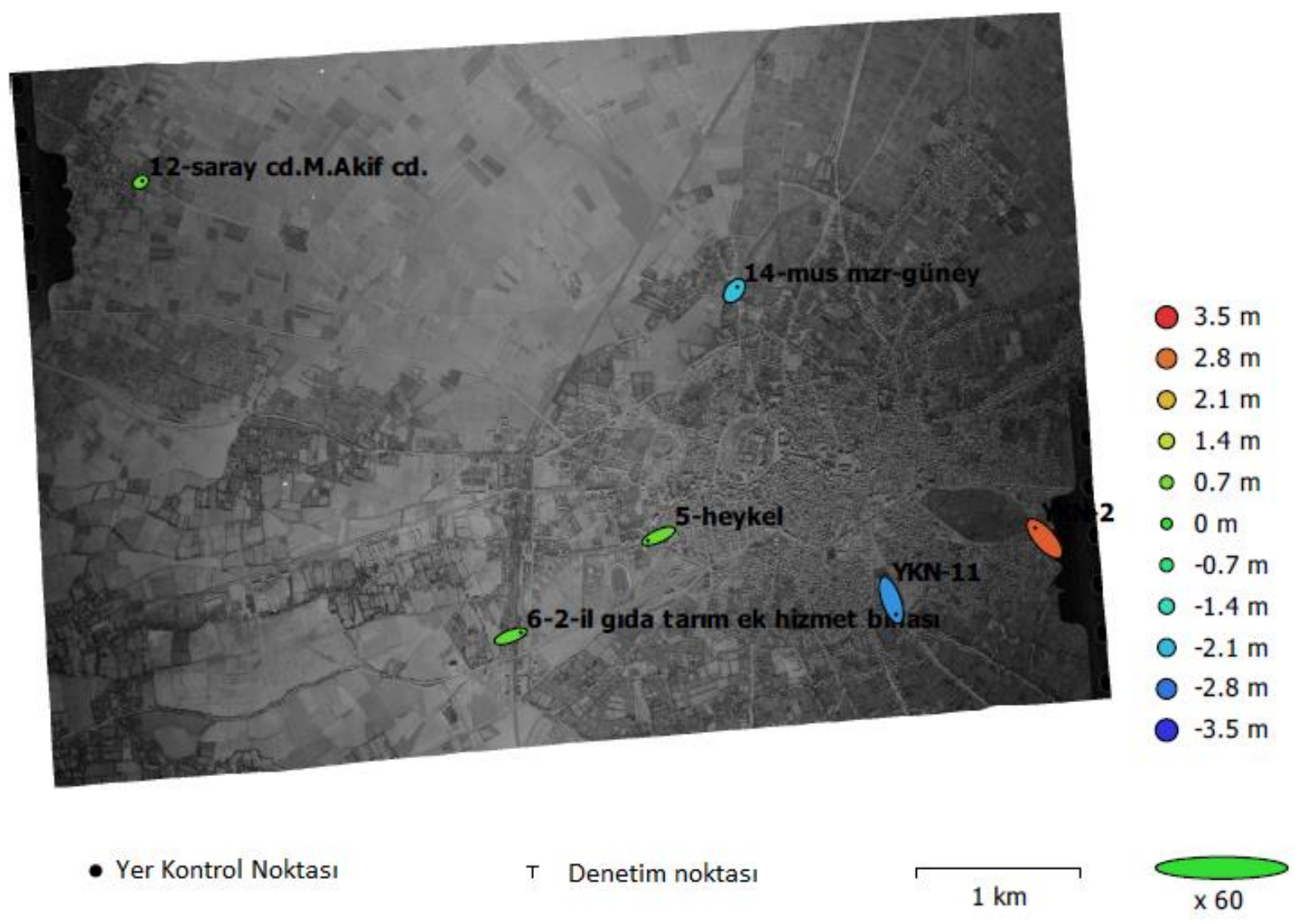

(a) 


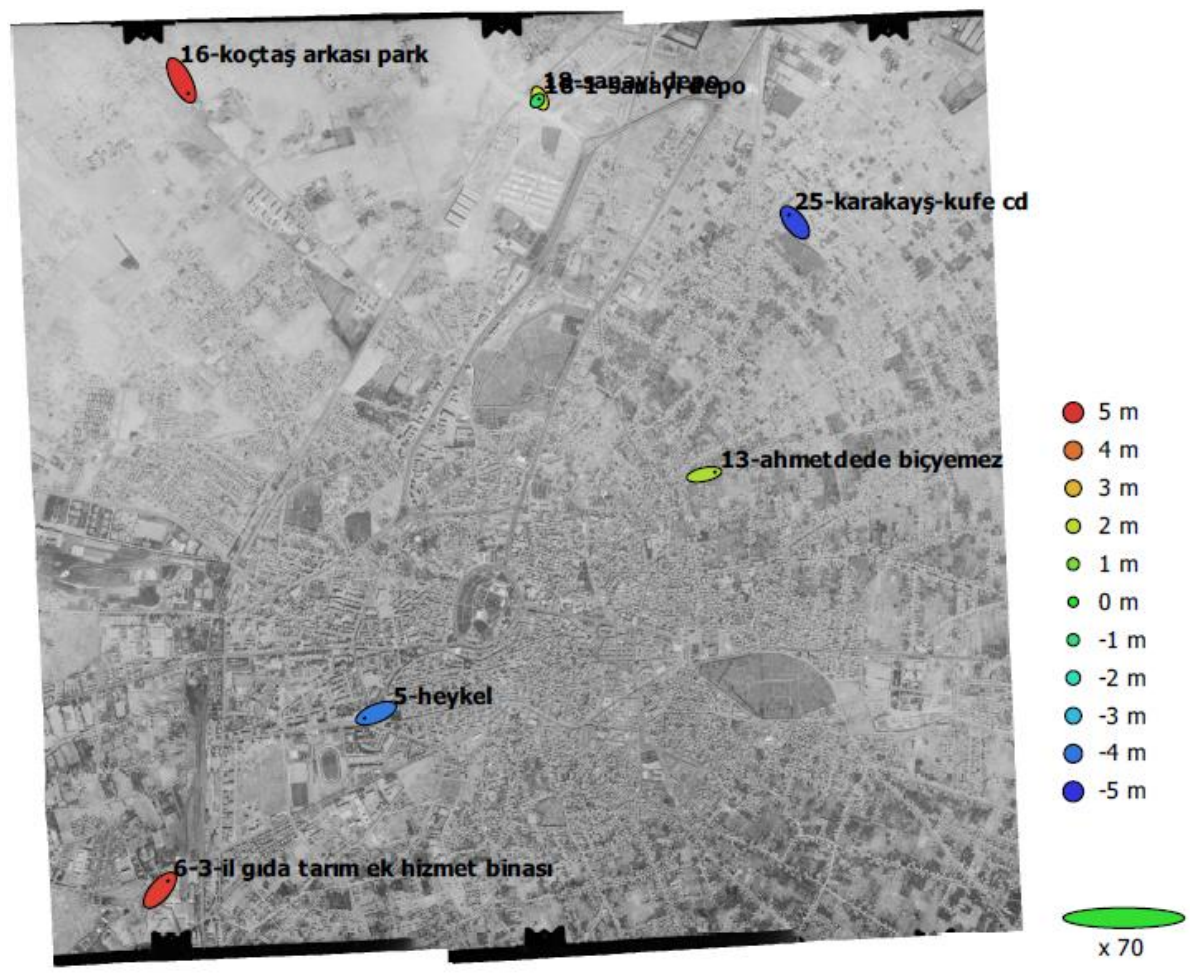

- Yer Kontrol Noktası

T Denetim Noktası

$1 \mathrm{~km}$

(b)

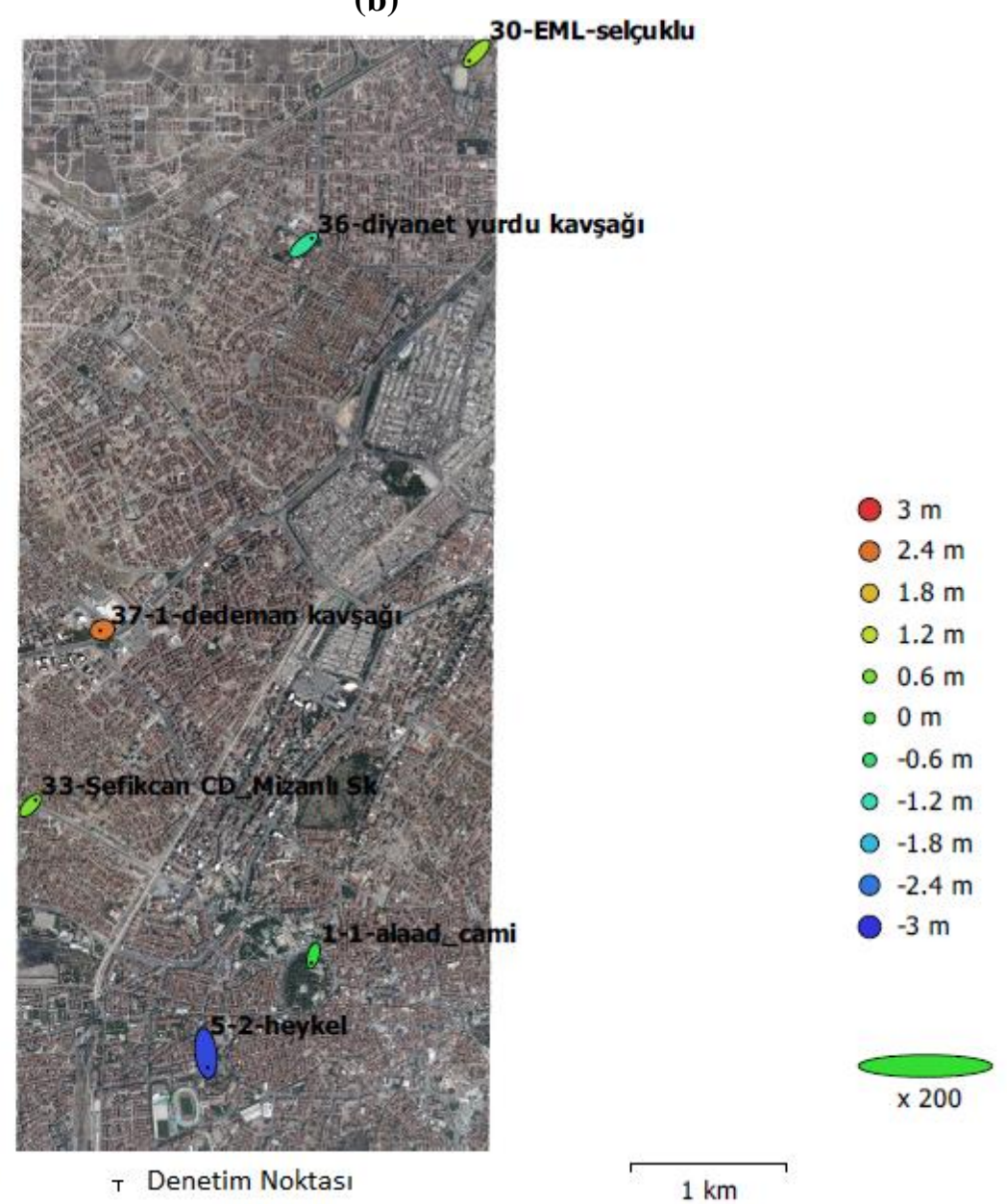

(c)

Şekil 4. (a) 1951, (b) 1975, (c) 2010 yılı nokta bulutlarının jeodezik koordinat sistemine dönüştürülmesinde kullanılan YKN ve oluşan hatalar. X,Y hataları elipsin büyüklüğü ile, Z yükseklik hataları ise yan tarafta verilen renkli lejant ile gösterilmiştir. 
Jeodezik koordinat sistemine dönüşümün doğruluğu YKN larında oluşan koordinat farklarının $\mathrm{KOH}$ 'sı ile ifade edilir (Tablo 3).

$$
\begin{aligned}
& K O H_{Z}=\sqrt{\frac{\sum\left(z_{s}-z_{r}\right)^{2}}{n}} \\
& K O H_{X Y}=\sqrt{\frac{\sum\left(x_{S}-x_{r}\right)^{2}+\sum\left(y_{s}-y_{r}\right)^{2}}{n}} \\
& K O H_{X Y Z}=\sqrt{\frac{\sum\left(x_{S}-x_{r}\right)^{2}+\sum\left(y_{s}-y_{r}\right)^{2}+\sum\left(z_{S}-z_{r}\right)^{2}}{n}}
\end{aligned}
$$

Bu eşitliklerde alt indis $s$ ve $r$, YKN'nın sırasıyla ölçülen ve dönüşüm parametreleri ile hesaplanan koordinatlarını ifade etmektedir. $n$, YKN sayısıdır. Tablo 3 de "Resim düzlemi" sütunundaki değerler her görüntü seti için hesaplanan parametrelerle yer kontrol noktalarının resim düzlemindeki konumlarında oluşan hataların (reprojection) $\mathrm{KOH}^{\prime}$ sinı ifade etmektedir. Bu hatanın 1 piksel ve daha düşük değerde olması da jeodezik koordinatlandırma doğruluğunun yeterli seviyede olduğunu göstermektedir.

Tablo 3. YKN koordinat farkları ve KOH [m]

\begin{tabular}{llllll}
\hline Tarih & YKN\# & $\mathbf{K O H}_{\mathbf{Z}}$ & $\mathbf{K O H}_{\mathbf{X Y}}$ & $\mathbf{K O H}_{\mathbf{X Y Z}}$ & $\begin{array}{l}\text { Resim } \\
\text { düzlemi } \\
\text { (piksel) }\end{array}$ \\
\hline 1951 & 6 & 1.86482 & 2.21835 & 2.8980 & 1.123 \\
1975 & 7 & 3.66713 & 1.50131 & 3.96255 & 0.437 \\
2010 & 6 & 1.62285 & 0.61077 & 1.73398 & 0.280 \\
\hline
\end{tabular}

\subsection{Değişimlerin Görüntülenmesi}

Jeodezik koordinat sistemine dönüşüm ile ölçüler ortak bir sistemde ifade edilmiş olur. Ancak YKN'larının tanımlanması, ölçülmesi ve diğer hatalar nedeniyle bir miktar dönüşüm hatası olacaktır. Dönüşümden sonra YKN'larındaki koordinat farkları da bunu göstermektedir. $\mathrm{Bu}$ nedenle değişim tespit edilecek periyotlar arasında jeodezik koordinat dönüşümünden kaynaklanan bir fark oluşacaktır. Bu farkın iki periyot arasında sayısal yükseklik modeli farkları ile hesaplanacak değişimi etkilememesi için karşılaştırma yapılan nokta bulutlarının birbirlerine göre hassas yöneltmesi yapılmıştır. Böylece iki farklı periyot nokta bulutu arasındaki değişimin daha yüksek doğrulukla hesaplanması sağlanmıştır. Değişim incelenecek tarih aralığının eski tarihli ölçüsü referans (sabit) diğeri hedef (referans sisteme dönüştürülecek) seçilerek hedef nokta bulutunun referans sisteme dönüşümü İEYN metodu ile gerçekleştirilmiştir. Daha sonra hedef ölçüye ait noktaların referans nokta bulutu üçgen yüzeyine (mesh) olan düşey mesafeleri saplanarak 1951$1975,1975-2010$ ve 1951-2010 tarihleri arasinda oluşan değişimler görüntülenmiştir (Şekil 5).

\section{Tartışma}

Her nokta bulutunun jeodezik koordinat sistemine dönüşümü için uygun dağılımda en az üç YKN gereklidir.
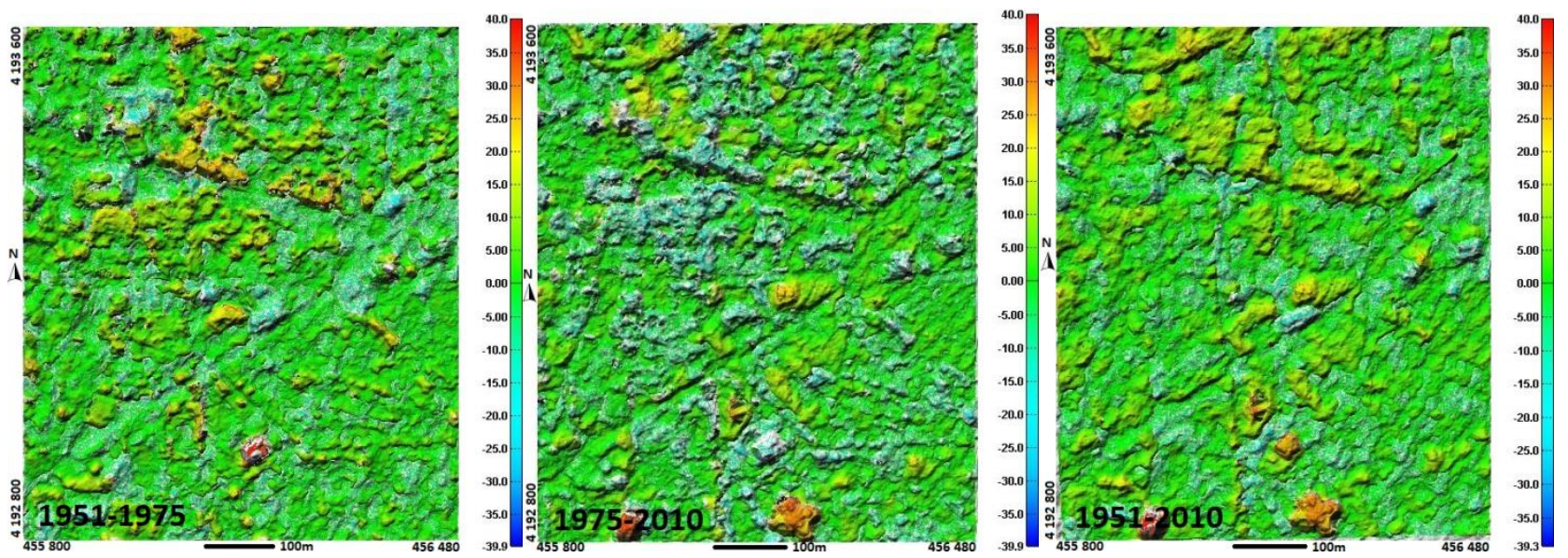

Şekil 5. 1951-1975, 1975-2010 ve 1951-2010 tarihleri arasında oluşan değişiklikler. İlk tarih ve ikinci tarih arasında oluşan yükseklik değişimin büyüklüğü ve yönü lejant ile ifade edilmiştir.

$\mathrm{Bu}$ çalışmada görüntü alanındaki detaylar daha fazla sayıda YKN tesis edilmesine olanak sağlamıştır. Detay esaslı YKN tesisi özellikle bina içermeyen eski tarihli görüntüler için oldukça zordur. Bu tür alanlarda yol, akarsu gibi doğal özelliklerden yararlanılarak kontrol noktası tesis 
edilebilir. Ancak bu tür doğal detayların belirgin özellikleri olan noktalarını bulmak zordur ve fotoğrafta ve mevcut durumda yeterli doğrulukta tanımlanamaz. YKN tesisinde karşılaşılan diğer bir problem GPS sinyali alınamadığı durumlarda koordinat ölçüsünün yapılamamasıdır. Sinyal alınamayan noktalarda uygun konumda başka detay noktaları seçilmiştir. Elde edilen koordinat farkları ve dönüşüm hataları jeodezik koordinat sistemine dönüşümün yüksek doğrulukta yapıldığını göstermektedir (Tablo 3).

Çalışma bölgesinde oluşan değişiklikler ortofoto görüntülerden de açıkça görülmektedir. 1951 tarihli görüntüde Alaaddin Tepesi'ni Mevlana Müzesi'ne bağlayan cadde yok iken 1975 ve 2010 tarihli görüntülerde caddenin bugünkü şeklini aldığı görülmektedir (Şekil 6). Mevlana Müzesi yanındaki Sultan Selim Cami'nin kuzey tarafında 1951 tarihinde park ve yüksek ağaçlar bulunmaz ikin 2010 tarihinde bu alanda bulunan yüksekliği
$20 \mathrm{~m}$ ye ulaşan ağaçların bulunduğu görüntülerin karşılaş̧ırılmasından anlaşılmaktadır. $\mathrm{Bu}$ çalışmada önerilen yöntem ile değişikliklerin tespitinde önemli problemlerden birisi de ağaçların yapraklı ve yapraksız durumlarında oluşan farklılıklardır. Diğer yandan yeni binaların oluşturduğu değişiklikler de görüntülerin karşılaştırılmasından açıkça görülmektedir. 9 katlı Kizılay Hastanesi ve 8 katlı Karatay Belediye Binas1 1975-2010 yılları arasında yapılmıștır. Bu tarihlere ait sayısal yükseklik modellerinin karşılaştırılması ile bu binaların oluşturduğu değişimler görülmektedir (Şekil 7). Değiş̧iklikler hem ortofoto hem de nokta bulutlarının karşılaştırılması ile elde edilen görüntülerden anlaşılabilmektedir. Ancak ortofoto görüntüden sadece görsel değişimler fark edilebilir. Oysa nokta bulutlarının karşılaştırılması yönteminde oluşan değişikliklerin yüksseklik olarak miktarları ve yönleri de görülebilmektedir.
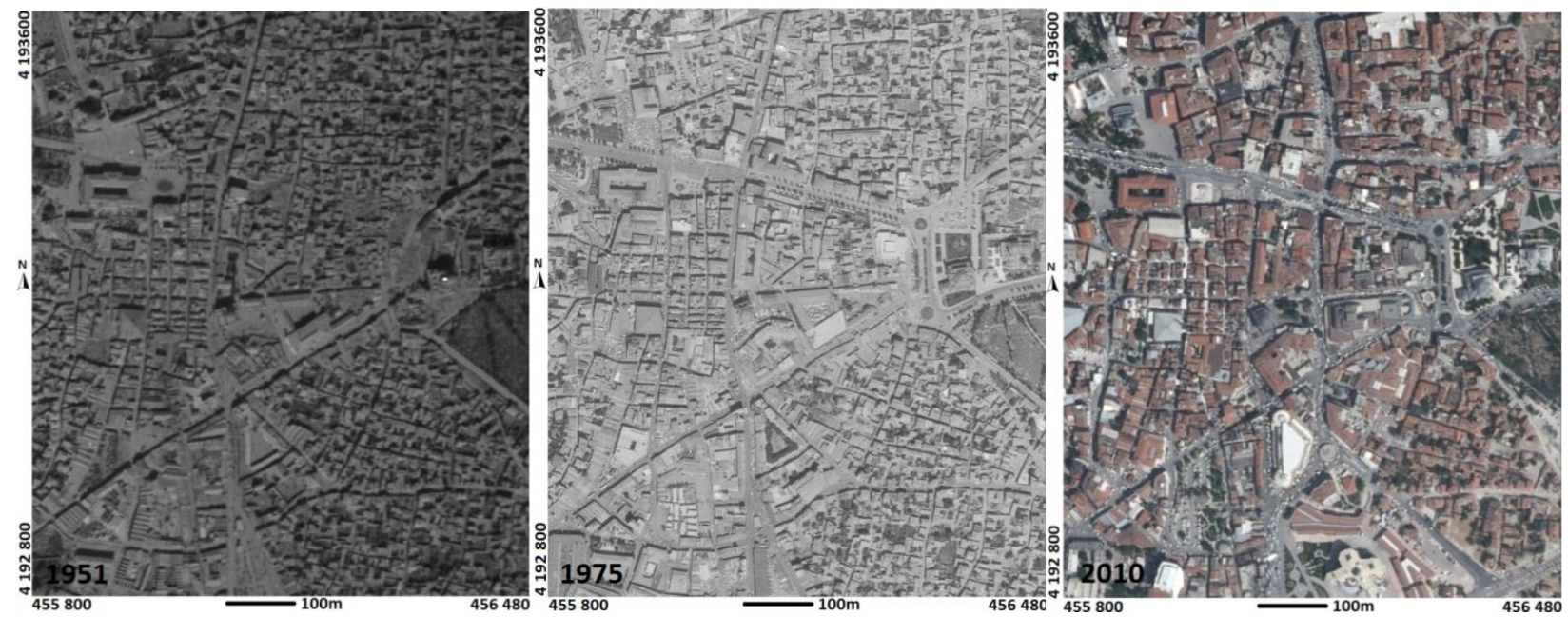

Şekil 6. 1951 (73cm çözünürlük), 1975 (40cm çözünürlük) ve 2010 (50cm çözünürlük) tarihli ortofoto görüntüler

Şekil 7. Kentsel değişimlerin sayısal yükseklik modellerinin farkları ile görüntülenmesi. Mevlana Müzesi civarında 1951-2010 arasında önemli bir değişim gözlenmemektedir. Diğer yandan Karatay Belediye Binas1 ve Kizılay Hastanesi'nin ortalama $30 \mathrm{~m}$ civarındaki yükseklik değişimi oluşturduğu görülmektedir.
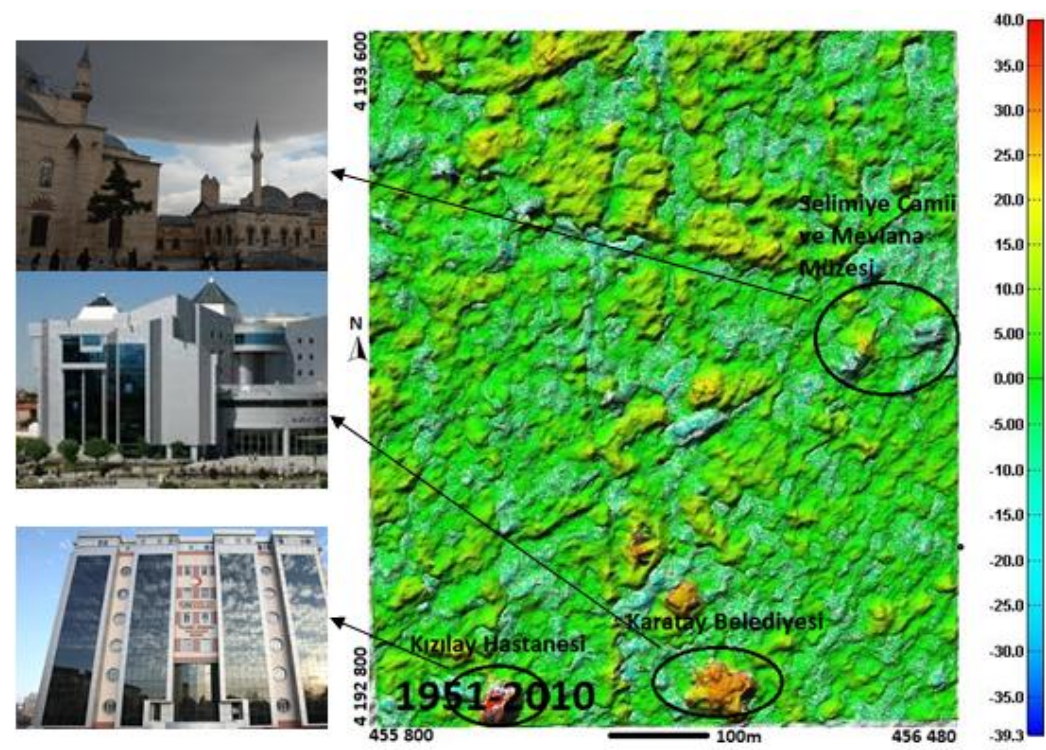


\section{Sonuç}

Bu çalışmada, belirli zaman aralığında kaydedilen hava fotoğraflarından oluşturulan fotogrametrik nokta bulutları karşılaştırılarak kentsel alanda meydana gelen değişiklikler görüntülenmiştir. Değişikliklerin tespitinde nokta bulutlarının oluşturduğu yüzeyler arasındaki mesafeler kullanılmıştır. İEYN yöntemi ile nokta bulutları birleştirildikten sonra bunlar arasındaki değişiklikleri ifade eden farklar hedef nokta bulutu noktalarından referans ölçünün üçgen yüzeyi elemanlarına olan düşey mesafelerle hesaplanmıştır. $\mathrm{Bu}$ çalışmada önerilen yöntem kentsel alanda meydana gelen büyük ölçekli değişimlerin tespit edilebilmesi için kolay ve düşük maliyetli bir yöntemdir. Bunun yanında gelişen insansız hava araçları ile görüntüleme, yöntemin uygulanmasında pek çok olanak sunmaktadır. İHA görüntüleri gibi büyük ölçekli görüntüler kullanılarak daha küçük değişikliklerin tespiti yapılabilecektir. Diğer yandan görüntüleme periyodu sıklaştırılarak değişiklikler daha kısa sürede tespit edilebilir ve kentsel alanda daha etkin bir denetleme yapılabilir.

\section{Bildirim ve Kabul}

$\mathrm{Bu}$ çalışmada kullanılan hava fotoğrafları Selçuk Üniversitesi BAP koordinatörlüğü tarafindan desteklenen 17401062 nolu projeden sağlanmıştır.

\section{Kaynaklar}

Al-Rawabdeh, A., Moussa, A., Foroutan, M., ElSheimy, N. ve Habib, A., 2017. Time series UAV image-based point clouds for land slide progression evaluation applications. Sensors, 17, paper no 2378 doi:10.3390/s 17102378

Awrangjeba, M.,Fraser, C.S. ve Lua, G., 2015. Building change detection from LiDAR point cloud data based on connected component analysis. ISPRS Annals of the Photogrammetry, Remote Sensing and Spatial Information Sciences, Volume II-3/W5, 2015 ISPRS Geospatial Week 2015, 28 Sep - 03 Oct 2015, La Grande Motte, France, pp. 393-400.

Barnhart, T.B. ve Crosby, B.T., 2013. Comparing two methods of surface change detection on an evolving thermokarstusing high-temporalfrequency terrestrial laser scanning. Selawik River, Alaska. Remote Sensing, 5(6), 28132837. doi:10.3390/rs5062813

Basgall, P.L.,Kruse, F.A. ve Olsen, R.C., 2014. Comparison of LiDAR and stereo photogrammetric point clouds for change detection. Laser Radar Technology and
Applications XIX; and Atmospheric Propagation XI, Editedby Monte D. Turner, Gary W. Kamerman, Linda M. Wasiczko Thomas, Earl J. Spillar, Proc. of SPIE Vol. 9080, 90800R, doi: 10.1117/12.2049856

Bildirici, I.O., Ustun, A., Selvi, H.Z., Abbak, R.A. ve Bugdayci, I., 2009. Assessment of shuttle radar topography mission elevation data based on topographic maps in Turkey. Cartography and Geographic Information Science, 36(1), 95-104.

Chen, Y. ve Medioni, G., 1992. Object modelling by registration of multiple range images. Image and Vision Computing, 10(3), 145-155.

Cusicanqui, J., 2016. 3D scenere construction and structural dmage assesment with aerial video frames and drone still imagery. Msc. Thesis, University of Twente, Enschede, The Nedherlands, 58 pages

Du, S., Zhang, Y., Qin, R., Yang, Z., Zou, Z. ve Tang, Y., 2016. Building change detection using old aerial images and new LiDAR data. Remote Sensing, 8(12), 1030, doi:10.3390/rs8121030

Ghuffar, S., Szekely, B., Roncat. A. ve Pfeifer, N., 2013. Land slide displacement monitoring using $3 \mathrm{D}$ range flow on airborne and terrestrial LiDAR data. Remote Sensing, 5, 2720-2745, doi:10.3390/rs5062720

Haala, N., 2011. Multiray photogrammetry and dense image matching. Photogrammetric Week 11, Dieter Fritsch (Ed.), Wichmann/VDE Verlag, Belin \&Offenbach, pp. 185-195.

Hughes, M.L., McDowell, P.F. ve Marcus, W.A., 2006. Accuracy assessment of georectified aerial photographs: Implications for measuring lateral channel movement in a GIS. Geomorphology, 74(1-4), $1-16$.

Jensen, J.L.R. ve Mathews, A.J., 2016. Assessment of image-based point cloud products to generate a bare earth surface and estimate canopy heights in a woodland ecosystem. Remote Sensing, 8(1), 50, doi:10.3390/rs8010050

Leberl, F.,Irschara, A., Pock, T., Meixner, P., Gruber, M., Scholz, S. ve Wiechert, A., 2010. Point clouds: Lidar versus 3D vision. Photogrammetric Engineering \& Remote Sensing, 76(10), 1123-1134.

Nebiker, S., Lack, N. ve Deuber, M., 2014. Building change detection from historical aerial photographs using dense image matching and object-based image analysis. Remote Sensing, 6(9), 8310-8336, doi:10.3390/rs6098310

Pang, S., Hu, X., Cai, Z., Gong, J. ve Zhang, M., 2018. Building change detection from bi-temporal 
dense-matching point clouds and aerial images. Sensors, 2018, 18, 966; doi:10.3390/s18040966

Rosnell, T., ve Honkavaara, E., 2012. Point cloud generation from aerial image data acquired by a quadrocopter type micro unmanned aerial vehicle and a digital still camera. Sensors, 12, 453-480, doi:10.3390/s120100453

Scaioni, M., Roncella, R. ve Alba, M.I., 2013. Change detection and deformation analysis in point clouds: Application to rock face monitoring. Photogrammetric Engineering and Remote Sensing, 79(5), 441-455.

Sisto, D.A. ve Packalen, P., 2017. Forest change detection by using point clouds from dense image matching together with a LiDAR-derived terrain model. IEEE Journal of Selected Topics in Applied Earth Observations and Remote Sensing, 10(3), 1197-1206.

Tran, T.H.G., Ressl, C. ve Pfeifer, N., 2018. Integrated change detection and classification in urban areas based on airborne laser scanning point clouds. Sensors, 18(2), paper no 448, doi:10.3390/s18020448

Xiao, W.,Vallet, B., Brédif, M. ve Paparoditis, N., 2015. Street environment change detection from mobile laser scanning point clouds. ISPRS Journal of Photogrammetry and Remote Sensing, 107, 38-49.

Yang, M.D., Chao, C.F., Huang, K.S., Lu, L.Y. ve Chen, Y.P., 2013. Image-based 3D reconstruction and exploration in augmented reality. Automation in Construction, 33, 48-60.

Zhang, X., Glennie, C. ve Kusari, A., 2015. Change detection from differential airborne LiDAR using a weighted anisotropic iterative closest point algorithm. IEEE Journal of Selected Topics in Applied Earth Observations and Remote Sensing, 8(7), 3338-3346. 